\title{
Pulmonary atresia with intact ventricular septum: Strategy based on right ventricular morphology
}

Naoki Yoshimura, MD

Masahiro Yamaguchi, MDa

Hidetaka Ohashi, MD ${ }^{a}$

Yoshihiro Oshima, MDa

Shigeteru Oka, MD ${ }^{\mathrm{a}}$

Masahiro Yoshida, MD ${ }^{\mathrm{a}}$

Hirohisa Murakami, MDa

Teruo Tei, $M D^{\mathrm{b}}$
From the Departments of Cardiothoracic Surgery $^{\mathrm{a}}$ and Cardiology, ${ }^{\mathrm{b}}$ Kobe Children's Hospital, Kobe, Japan.

Received for publication Nov 25, 2002; revisions requested Feb 10, 2003; revisions received April 27, 2003; accepted for publication June 10, 2003.

Address for reprints: Naoki Yoshimura, MD, Department of Cardiothoracic Surgery, Kobe Children's Hospital, 1-1-1, Takakura-dai, Suma-ku, Kobe, 654-0081 Japan (E-mail: y-naoki@za2.so-net.ne.jp).

J Thorac Cardiovasc Surg 2003;126: $1417-26$

Copyright $(0) 2003$ by The American Association for Thoracic Surgery

$0022-5223 / 2003 \$ 30.00+0$

doi:10.1016/S0022-5223(03)01035-3
Objectives: Management strategy for pulmonary atresia with intact ventricular septum is controversial. We treated patients with this anomaly according to a management protocol based on our quantitative assessment of right ventricular morphology (index of right ventricular development and right ventricle-tricuspid valve index). In the present study, we reviewed a 20-year experience of the surgical treatment at our institution to define guidelines for selecting the appropriate type of surgical procedure.

Methods: Between April 1981 and June 2002, 45 consecutive patients with pulmonary atresia with intact ventricular septum underwent surgical treatment. Open transpulmonary valvotomy was performed in 27 patients and Blalock-Taussig shunt in 18 patients as the initial palliative procedure. Three patients who underwent a successful transpulmonary valvotomy alone in the neonatal period required no further operation. Definitive repair was performed in 32 patients. Biventricular repair was performed on 19 patients, one and a half ventricular repair in 3, and Fontan-type operation in 10.

Results: There were 1 early and 2 late deaths before the definitive operation in patients who underwent transpulmonary valvotomy. Two patients who had coronary artery interruption died 3 months and 13 years after the initial Blalock-Taussig shunt. There were 1 early and 2 late deaths after the definitive operation. Actuarial survival, including noncardiac death, was $91.1 \%$ at 5 years after the initial procedure and $81.5 \%$ at 10 years.

Conclusions: We treated patients with pulmonary atresia with intact ventricular septum according to a management protocol based on our quantitative assessment of right ventricular morphology with good results.

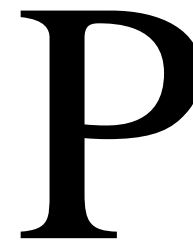
ulmonary atresia with intact ventricular septum (PA-IVS) has generally been difficult to manage, and surgical procedures for this anomaly were associated with high mortality and morbidity until recently. ${ }^{1-4}$ Various factors limiting the subsequent surgical outlook include size and morphology of the right ventricle, ${ }^{5,6}$ size and function of the tricuspid valve $, 7,8$ and presence or absence of right ventricle-dependent coronary circulation. ${ }^{9-11}$

The main goals of repair are to improve systemic arterial oxygenation and, whenever possible, establish forward flow through the right ventricle. ${ }^{12,13}$ Most institutes use a 2-stage approach to optimize growth of the right ventricle and tricuspid valve..$^{7-14}$ The initial operation, which includes a pulmonary valvoto- 
my, ${ }^{1,7,15-18}$ balloon valvuloplasty, ${ }^{19,20}$ or a right ventricular outflow tract patch, ${ }^{3,4,11,12}$ either alone or combined with a systemic-pulmonary artery shunt, establishes antegrade flow and promotes the growth of the right side of the heart. Selection of the definitive procedure, which is performed at 1 to 5 years of age, depends on the development of the right ventricle and tricuspid valve. If the sizes of the right ventricle and tricuspid valve are adequate, consideration should be given to biventricular repair. Patients with a small right ventricle and tricuspid valve, which do not grow after initial palliation, are not candidates for biventricular repair and instead should be considered for the Fontan procedure or one and a half ventricular repair. ${ }^{8,12,21-25}$

However, the criteria for determining an adequate procedure remains unclear for a range of borderline cases because the numerous physiologically based management protocols are not supported by surgical outcomes. ${ }^{5,8,11,26}$ Management protocols should be determined by the precisely estimated morphology of right ventricle and tricuspid valve, and the adequacy of the protocols should be analyzed by surgical outcomes.

We treated patients with PA-IVS according to a management protocol based on our quantitative assessment of right ventricular morphology. ${ }^{16,27}$ In the present study, we reviewed a 20-year experience of the surgical treatment of PA-IVS at our institution with 2 objectives: (1) to clarify the long-term results over the last 2 decades and (2) to define guidelines for selecting the appropriate type of surgical procedure.

\section{Patients and Methods \\ Patients}

Between April 1981 and June 2002, 45 consecutive patients underwent surgical treatment in our hospital. There were 25 boys and 20 girls, and birth weight ranged from 1650 to $3600 \mathrm{~g}$ (median: $3086 \mathrm{~g}$ ). All but 7 cases were first seen in the neonatal period and required operation for survival in the first admission. Right ventricle-to-coronary artery fistulas were present in 15 of 45 (33.3\%) patients. Seven patients had major and 8 had minor fistulas. Six patients had right ventricle-dependent coronary circulation. Three patients had complicated interruptions of coronary artery.

\section{Measurement}

Cardiac catheterization was performed in all but 2 children before the initial palliative operation. One patient was a premature infant whose body weight at the initial operation was $1950 \mathrm{~g}$, and another patient underwent an emergency Blalock-Taussig shunt for severe hypoxia that had been refractory to prostaglandin $\mathrm{E}_{1}$. Late follow-up catheterization before definitive surgery was performed in 35 patients.

Biplane right ventriculograms were performed in the posteroanterior and lateral projections. Right ventricular end-diastolic volume (RVEDV) was calculated using Simpson's rule and the linear regression equation of Graham and associates. ${ }^{28}$ The volume was then expressed as a percentage of expected normal values using the method of Nakazawa and associates. ${ }^{29}$ Tricuspid valve diameter (TVD) was measured from the right ventriculogram in the end-diastolic phase from the superior to the inferior rim of the annulus. The diameter was expressed as a percentage of the predicted diameter of the tricuspid valve derived from the Bull's modification ${ }^{30}$ of the autopsy data by Rowlatt. The diameter of the right ventricular outflow tract (RVOD) was measured at the narrowest portion in the lateral projection at the end-diastolic phase (Figure 1).

\section{Initial Palliations}

Since 1988, based on a retrospective review of the first 23 patients early in this series (between 1981 and 1987), the type of initial procedure has been decided in conformity with the value of calculated index of right ventricular development (RVDI), according to the following equation. ${ }^{16}$

$\mathrm{RVDI}=\operatorname{RVEDV}(\% \mathrm{~N})$

$$
\cdot \operatorname{TVD}(\% \mathrm{~N}) \cdot \operatorname{RVOD}(\mathrm{mm}) \cdot 10^{-5} / \mathrm{BSA}\left(\mathrm{m}^{2}\right)
$$

where BSA is body surface area.

In those patients with RVDI $>0.7$, transpulmonary valvotomy was performed as the palliative procedure. When RVDI was between 0.35 and 0.7 , in addition to transpulmonary valvotomy, $\beta$-blocker was administered to facilitate the weaning from prostaglandin E1. When RVDI was $<0.35$, Blalock-Taussig shunt was created simultaneously with the transpulmonary valvotomy. In cases with muscular atresia or right ventricle-dependent coronary circulation, only a Blalock-Taussig shunt was performed for initial palliation (Table 1). In 42 patients, right ventriculography was available for calculating RVDI.

Transpulmonary valvotomy ${ }^{16}$ was performed under direct vision through the main pulmonary artery without cardiopulmonary bypass. The heart was exposed through a median sternotomy (in patients who underwent valvotomy alone) or a left thoracotomy (in patients who underwent Blalock-Taussig shunt simultaneously with the valvotomy). A balloon catheter was inserted into the right ventricle through a buttress suture set on the right ventricular outflow tract. The balloon was then inflated and the catheter was wedged into the right ventricular outflow tract. The pulmonary trunk was then clamped as far distally as possible; however, care should be taken not to disturb the pulmonary blood flow through the duct. A longitudinal arteriotomy allows direct visualization of the atretic pulmonary valve. The pulmonary valve was sharply incised with a knife along each commissural fusion line. Postoperatively, prostaglandin $\mathrm{E}_{1}$ was continuously infused, with the duration of infusion based on improved systemic oxygen saturation consistent with additional pulmonary blood flow from a right ventricle. The amount of prostaglandin $\mathrm{E}_{1}$ was decreased gradually. When it was difficult to wean from prostaglandin $E_{1}$ by hypoxia, $\beta$-blocker was administered. ${ }^{31}$

\section{Definitive Repairs}

Before 1992, decisions concerning the strategy of definitive repair were based on the clinical assessment of the attending cardiologists and surgeons using data obtained from echocardiography and follow-up catheterization. Since 1992, based on the retrospective review, ${ }^{32}$ we developed a management protocol on the criteria for 

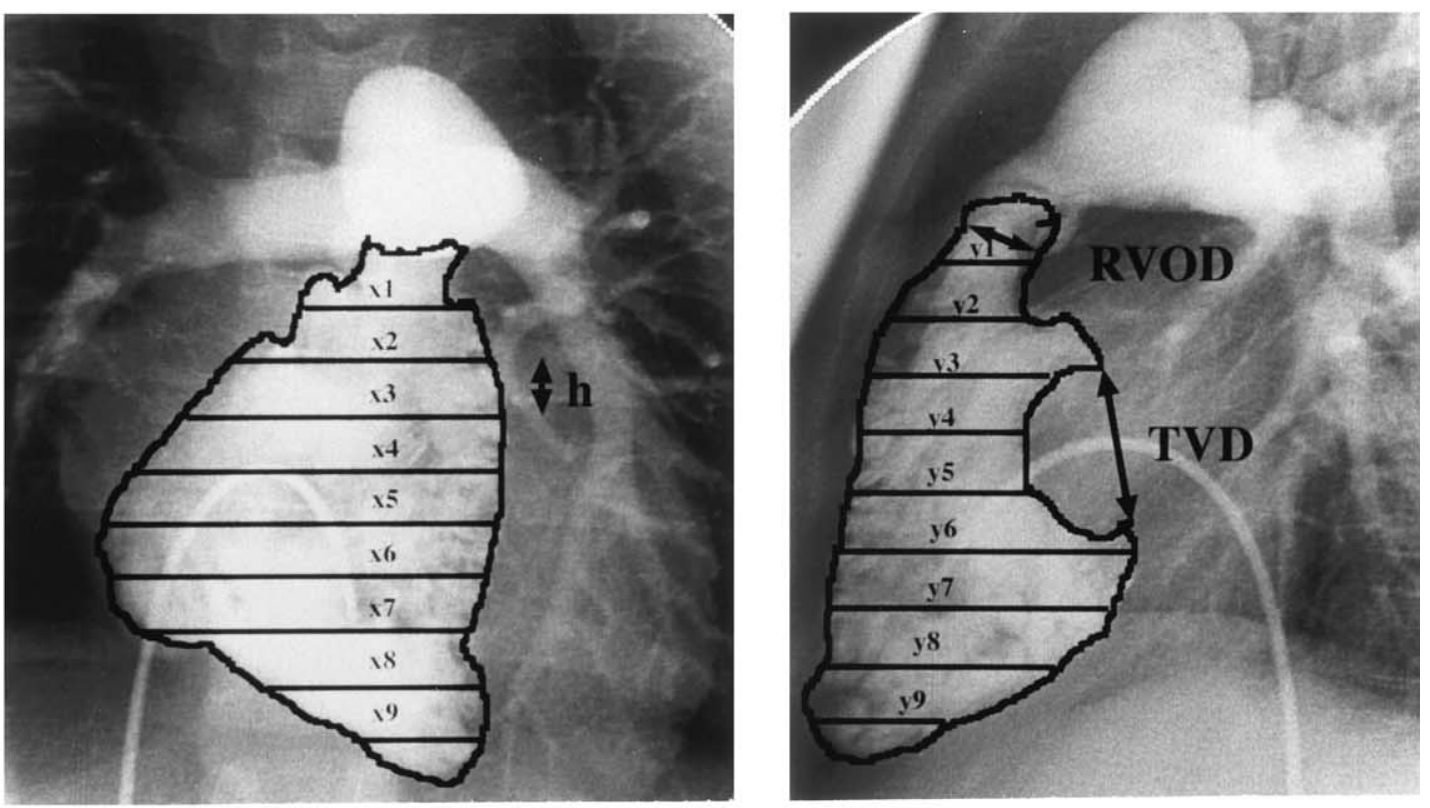

A

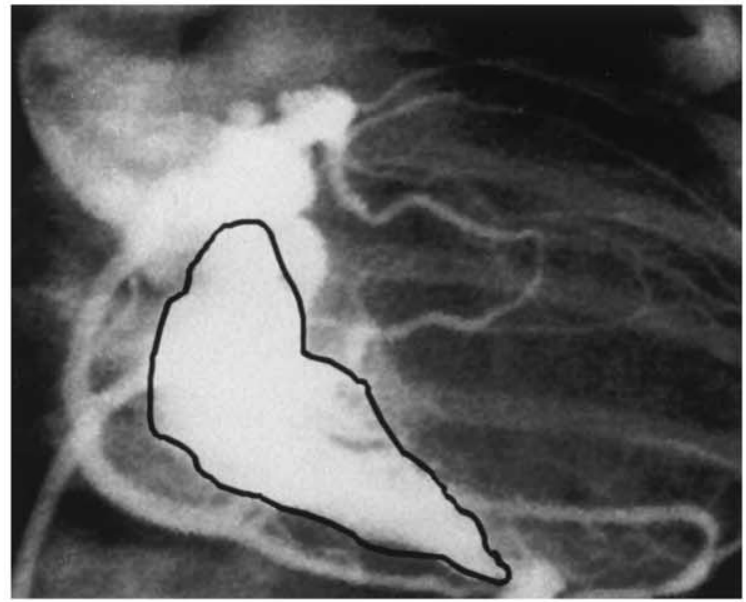

B

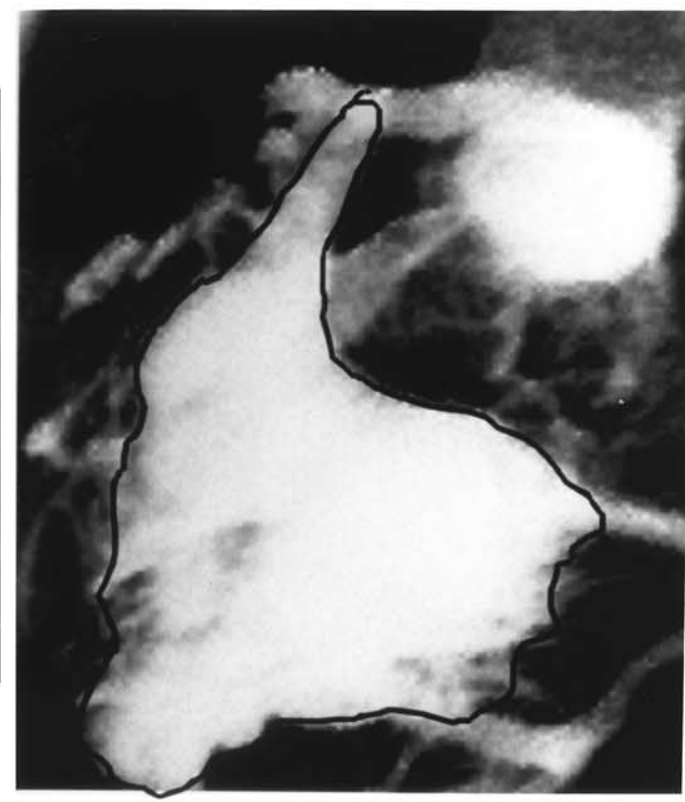

Figure 1. A, Calculations of RVEDV, tricuspid valve diameter (TVD), and diameter of the right ventricular outflow tract (RVOD). RVEDV $\left(\mathrm{cm}^{3}=[(x 1 y 1+x 3 y 3+\ldots+x 9 y 9)+1 / 2(x 2 y 2+\ldots+x 8 y 8)] \cdot 0.649 \pi \mathrm{h} / 3\right.$. Expected normal values of RVEDV $\left(\mathrm{cm}^{3}\right)=75.1 \cdot$ BSA $^{1.43}$ (Nakazawa). Expected normal values of TVD $(\mathrm{cm})=24.9+19 \operatorname{logBSA}$ (Rowlatt). Expected normal values of TVD $(\mathrm{cm})=1.43 \cdot$ Rowlatt +0.39 (Bull). B, Right ventriculogram of a 5-day-old boy with muscular atresia and right ventricle-dependent coronary circulation. RVEDV, TVD, and RVDI were $25.1 \% \mathrm{~N}, 25.3 \% \mathrm{~N}$, and 0.044 , respectively.

determining the procedure of definitive repair. The type of definitive repair has been decided in conformity with the calculated $\mathrm{RV}-\mathrm{TV}$ index value, according to the following equation. ${ }^{27}$

$\mathrm{RV}-\mathrm{TV}$ index $=\operatorname{RVEDV}(\% \mathrm{~N}) \cdot \operatorname{TVD}(\% \mathrm{~N}) \cdot 10^{-4}$
Complete biventricular repair, consisting of atrial septal defect (ASD) closure and right ventricular outflow tract reconstruction, was performed in patients who had RV-TV index $>0.4$. In patients with RV-TV index ranging between 0.2 and 0.4 , partial closure of ASD using a fenestrated patch and right ventricular 


\section{TABLE 1. Management protocol for patients with PA-IVS}

\begin{tabular}{|c|c|}
\hline Initial palliation & \\
\hline RVDI $>0.7$ & Valvotomy only \\
\hline $0.35<\mathrm{RVDI}<0.7$ & Valvotomy and $\beta$-blocker \\
\hline RVDI $<0.35$ & $\begin{array}{l}\text { Concomitant valvotomy and } \\
\text { Blalock-Taussig shunt }\end{array}$ \\
\hline $\begin{array}{l}\text { Muscular atresia of } \\
\text { RVOT } \pm \text { major RV-CA } \\
\text { fistulas }\end{array}$ & Blalock-Taussig shunt \\
\hline Definitive repair & \\
\hline RV-TV index $>0.4$ & Complete biventricular repair \\
\hline $0.2<\mathrm{RV}$-TV index $<0.4$ & $\begin{array}{l}\text { Biventricular repair with partial } \\
\text { closure of ASD }\end{array}$ \\
\hline $\begin{array}{l}0.1<\mathrm{RV}-\mathrm{TV} \text { index }<0.2 \\
\text { RV-TV index }<0.1\end{array}$ & $\begin{array}{l}\text { One and a half ventricular repair } \\
\text { Fontan-type operation }\end{array}$ \\
\hline
\end{tabular}

$R V D I$, Index of right ventricular development; RVOT, right ventricular outflow tract; $R V-C A$, right ventricle-coronary artery; $R V-T V$, right ventricletricuspid valve.

outflow tract reconstruction were performed. When RV-TV index ranged between 0.1 and 0.2 , one and a half ventricular repair consisting of right ventricular outflow tract reconstruction, partial closure of ASD, and bidirectional Glenn anastomosis was performed. In patients with RV-TV index $<0.1$, Fontan-type procedure was performed (Table 1).

In 34 of 35 patients who underwent follow-up catheterization, right ventriculography was available for calculating the RV-TV index.

\section{Follow-up}

All patients were followed up through clinic visits. The mean follow-up period after the first palliative procedure was 117 months (range: 0-242 months) and the end of the follow-up study was September 2002. Kaplan-Meier survival analysis was used to evaluate the survival.

\section{Results}

\section{Initial Palliations and Subsequent Interventions}

Open transpulmonary valvotomy was performed in 27 patients as the initial palliative procedure. Age at the time of operation ranged from 1 day to 4 months (median: 9 days). In this group of patients, RVEDV, TVD, and RVOD ranged from $13.0 \% \mathrm{~N}$ to $89.0 \% \mathrm{~N}$ (median: $33.0 \% \mathrm{~N}$ ), $33.2 \% \mathrm{~N}$ to $98.0 \% \mathrm{~N}$ (median: $60.0 \% \mathrm{~N}$ ), and 2.6 to $8.8 \mathrm{~mm}$ (median: 3.9 $\mathrm{mm}$ ), respectively. There was 1 operative death after the initial transpulmonary valvotomy (early mortality: $3.7 \%$ ). This patient, who was the first case in our series, died of renal failure and intracranial bleeding, which had been present preoperatively. There were 7 patients who had uneventful clinical courses after an initial transpulmonary valvotomy alone. The RVDI exceeded 0.7 in these 7 patients. There were 6 patients who required $\beta$-blocker to be weaned from prostaglandin $E_{1}$. RVDI in these patients ranged from 0.36 to 0.64 . Early in this series, 6 additional BlalockTaussig shunts were performed in 4 patients at an interval of
7 days to 3 years after the transpulmonary valvotomy. In 3 of these 4 patients, RVDI was lower than 0.35. Another patient whose RVDI was 0.77 underwent Blalock-Taussig shunt as an emergent procedure because of hypoxia following precipitous cessation of prostaglandin $\mathrm{E}_{1}$. This patient had been in congestive heart failure due to excessive pulmonary blood flow for several months after the creation of Blalock-Taussig shunt. In retrospect, we believe that this patient could have been managed with transpulmonary valvotomy alone if gradual reduction of prostaglandin $\mathrm{E}_{1}$ had been attempted over 3 to 5 days, as is now our practice. Since 1991, 9 patients whose RVDI was lower than 0.35 underwent concomitant transpulmonary valvotomy and Blalock-Taussig shunt. There were 2 late deaths before the definitive operation in patients who underwent transpulmonary valvotomy. One patient died of severe viral infection, and another died suddenly at home (Figure 2).

Blalock-Taussig shunt was performed in 18 patients as the initial palliative procedure. Age at the time of operation ranged from 2 days to 5 months (median: 2 months). In this group of patients, RVEDV and TVD ranged from $7.0 \% \mathrm{~N}$ to $28.0 \% \mathrm{~N}$ (median: $15.0 \% \mathrm{~N}$ ) and $23.0 \% \mathrm{~N}$ to $55.0 \% \mathrm{~N}$ (median: $44.0 \% \mathrm{~N})$, respectively. There were no operative deaths after the initial Blalock-Taussig shunt. There were 2 patients who underwent transpulmonary valvotomy after Blalock-Taussig shunt. One patient had the initial BlalockTaussig shunt at another institution. Another patient underwent an emergency Blalock-Taussig shunt for severe hypoxia that had been refractory to prostaglandin $E_{1}$ at 2 days of age. Cardiac catheterization and subsequent transpulmonary valvotomy were performed at 1 month of age. Two patients who had coronary artery interruption died 3 months and 13 years after the initial Blalock-Taussig shunt (Figure 2).

\section{Definitive Repairs}

Three patients who underwent a successful transpulmonary valvotomy alone in the neonatal period required no further operation. Right ventricles of these 3 patients developed well (RVEDV: $122.0 \% \mathrm{~N}, 94.0 \% \mathrm{~N}$, and $74.0 \% \mathrm{~N}$ ), and atrial septal defects were closed spontaneously in the follow-up catheterizations. One of these 3 patients underwent balloon valvuloplasty for pulmonary stenosis with a good result (Figure 2).

Definitive repair was performed in 32 patients. Age at the time of operation ranged from 1 to 9 (median: 4) years. There was 1 operative death (early mortality: $3.1 \%$ ). A 6-year-old girl who had renal dysfunction preoperatively underwent right ventricular outflow tract reconstruction, partial closure of ASD, and ligations of major right ventricle-to-coronary artery fistulas. This patient died of low cardiac output syndrome and acute renal failure. 


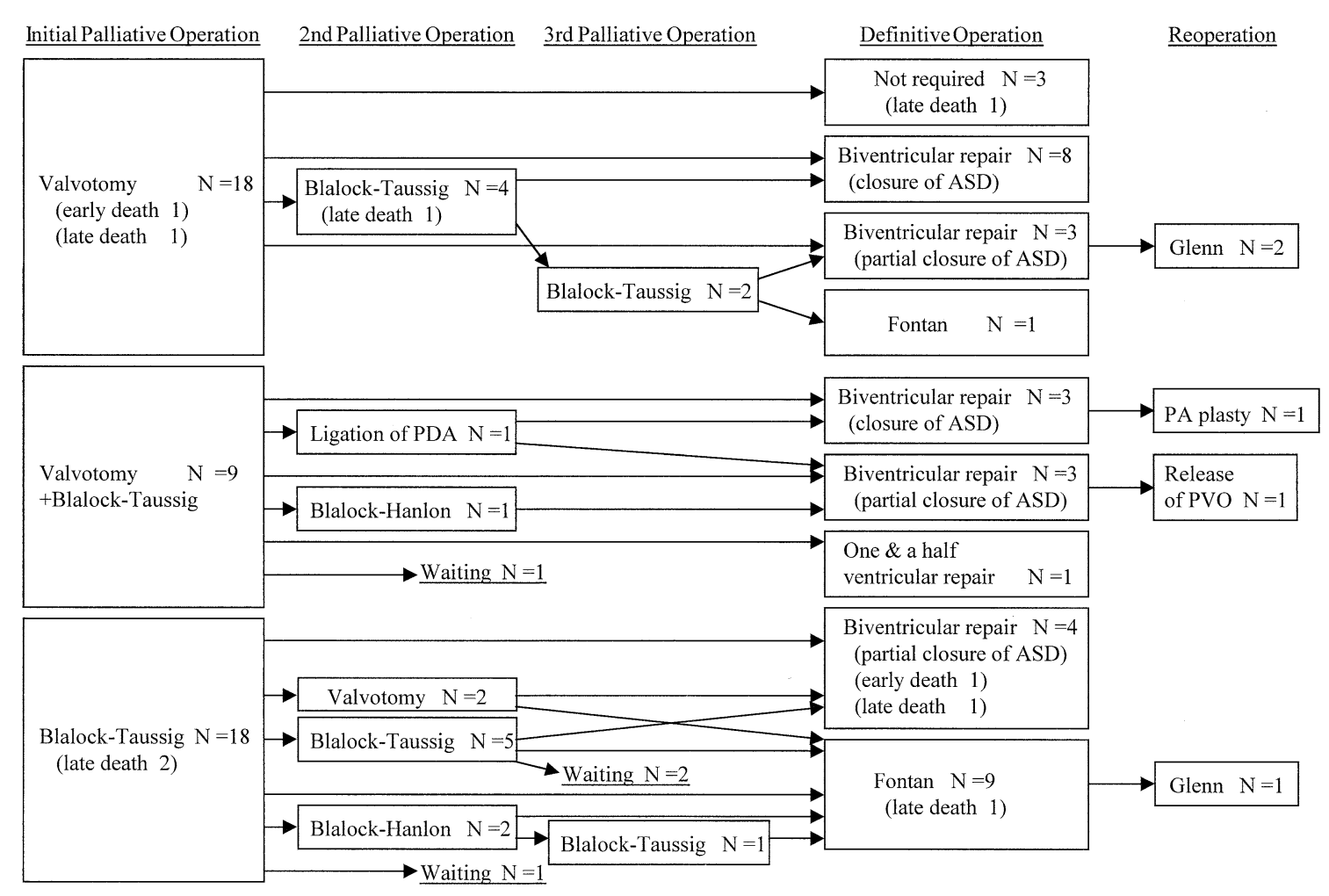

Figure 2. Flow chart of surgical outcomes. PDA, Patent ductus arteriosus; $A S D$, atrial septal defect; $P A$, pulmonary artery; PVO, pulmonary venous obstruction.

Right ventricular outflow tract reconstruction with closure of ASD and all existing palliative shunts was performed on 11 patients (Figure 2). Six of the 11 patients required only revalvotomy to reconstruct the right ventricular outflow tract. In 3 patients, right ventricular outflow tract was reconstructed using a transannular patch. In the other 2 patients, revalvotomy and resection of hypertrophied infundibulum were performed. Three patients underwent tricuspid valvuloplasty, and 4 patients required repair for branch stenosis of the pulmonary artery. RVEDV and TVD ranged from $72.0 \% \mathrm{~N}$ to $100.0 \% \mathrm{~N}$ (median: $82.3 \% \mathrm{~N}$ ) and $55.0 \% \mathrm{~N}$ to $90.0 \% \mathrm{~N}$ (median: $74.0 \% \mathrm{~N}$ ), respectively. RV-TV index was $>0.4$ in these 11 patients (Figure 3). Postoperative cardiac catheterization was performed in these 11 patients 1 month after the operation. The postoperative right ventricular systolic pressure and the systolic pressure gradient across the right ventricular outflow tract ranged from 21 to $57 \mathrm{~mm} \mathrm{Hg}$ (median: $37 \mathrm{~mm} \mathrm{Hg}$ ) and 1 to $39 \mathrm{~mm} \mathrm{Hg}$ (median: $12 \mathrm{~mm} \mathrm{Hg}$ ), respectively.

Right ventricular outflow tract reconstruction with partial closure of ASD was performed on 8 patients (Figure 2). Right ventricular outflow tract was reconstructed using a transannular patch. In 2 of these patients, muscle resection of infundibulum (right ventricular overhaul ${ }^{14,18}$ ) was performed concomitantly. Tricuspid valvuloplasty, ligation of right ventricle-to-coronary artery fistulas, and plasty of pulmonary artery were performed in 4, 2, and 1 patients, respectively. RVEDV and TVD ranged from $35.0 \% \mathrm{~N}$ to $69.0 \% \mathrm{~N}$ (median: $42.7 \% \mathrm{~N}$ ) and $47.0 \% \mathrm{~N}$ to $67.0 \% \mathrm{~N}$ (median: $58.6 \% \mathrm{~N}$ ), respectively. RV-TV index ranged from 0.206 to 0.360 in these 8 patients (Figure 3). The postoperative right ventricular systolic pressure and the systolic pressure gradient across the right ventricular outflow tract in 7 patients who survived the operation ranged from 12 to 41 mm Hg (median: $30 \mathrm{~mm} \mathrm{Hg}$ ) and 0 to $18 \mathrm{~mm} \mathrm{Hg}$ (median: $4 \mathrm{~mm} \mathrm{Hg}$ ), respectively. The postoperative systemic oxygen saturation in these 7 patients ranged from $85 \%$ to $92 \%$ (median: 89\%). Three of these 7 patients have no evidence of an ASD on follow-up echocardiography and have arterial saturation of $95 \%$ or over. None of these patients show evidence of thrombus formation at the site of the ASD.

One and a half ventricular repair was performed in 3 patients (Figure 2). RVEDV, TVD, and RV-TV index of the first patient were $30.0 \%, 55.0 \%$, and 0.165 , respectively. This patient underwent reconstruction of the right ventricular outflow tract, resection of infundibular fibrous tissue, partial closure of ASD, tricuspid commissurotomy, and closure of bilateral Blalock-Taussig shunts at 8 year of age. The postoperative right ventricular systolic pressure and systemic oxygen saturation were $61 \mathrm{~mm} \mathrm{Hg}$ and $67 \%$, 


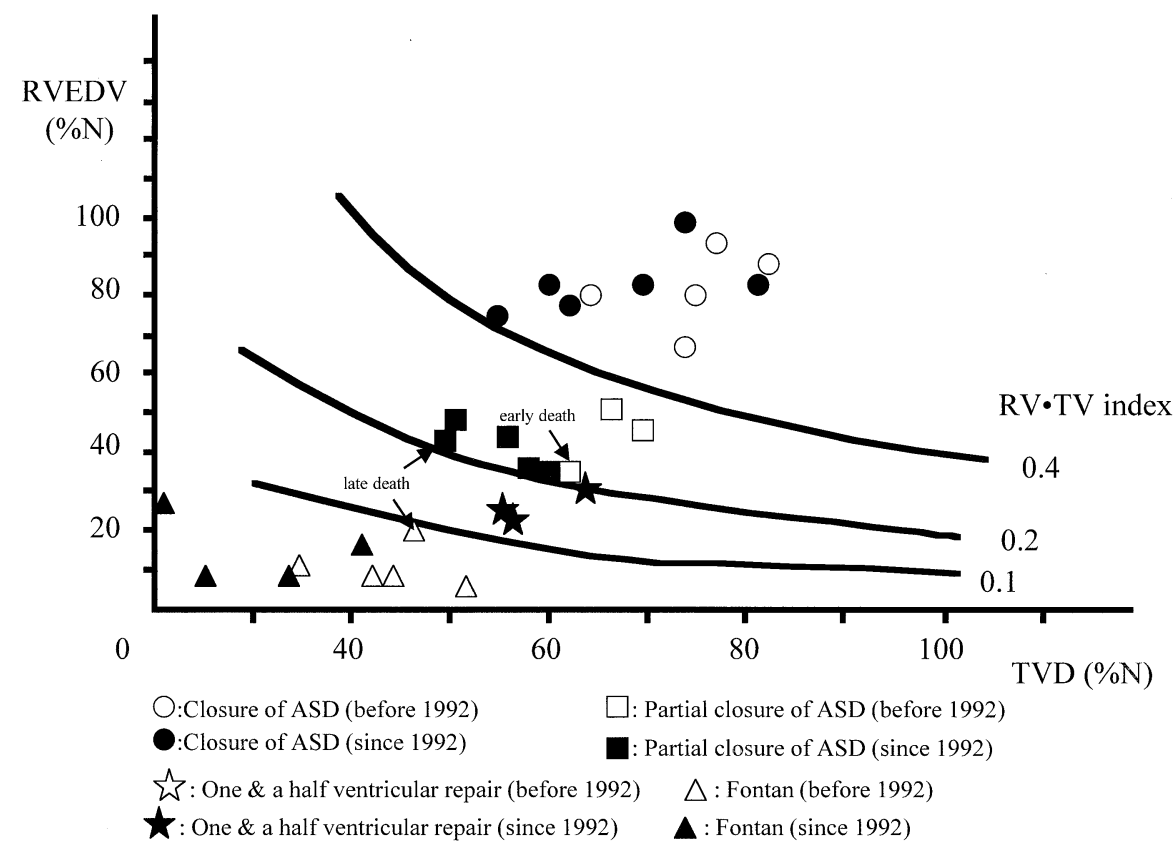

Figure 3. RVEDV, TVD, RV-TV index, and type of definitive repair. RVEDV, Right ventricular end-diastolic volume; TVD, tricuspid valve diameter.

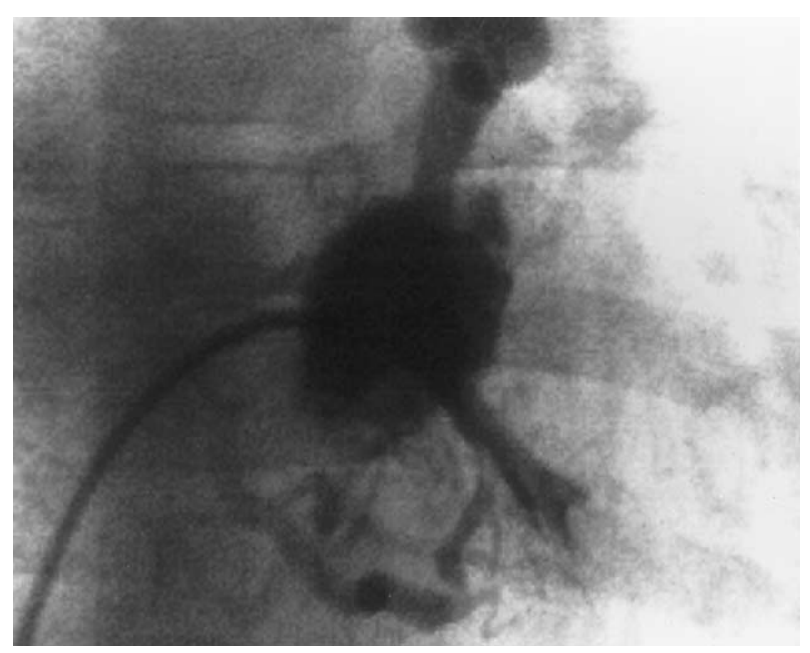

Figure 4. Right ventriculogram of a patient who underwent one and a half ventricular repair. RVEDV, TVD, and RV-TV index were $26.6 \%, 55.7 \%$, and 0.148 , respectively.

respectively. Cyanosis continued after she was discharged from the hospital. Follow-up catheterization was performed 6 years after the operation. RVEDV, TVD, and RV-TV index decreased to $15.3 \%, 53.3 \%$, and 0.082 . This patient underwent bidirectional Glenn shunt at 15 years of age. Now, she is doing well 2 years after the Glenn shunt operation. A second patient underwent initial transpulmonary valvotomy at 4 months of age. RVEDV, TVD, and
RV-TV index before the definitive repair were $35.0 \%$, $64.0 \%$, and 0.224 , respectively. This patient underwent revalvotomy and partial closure of ASD at 5 years of age. Follow-up catheterization was performed 6 years after the operation because she showed signs of right heart failure. RVEDV, TVD, and RV-TV index decreased to $28.5 \%$, $61.6 \%$, and 0.175 . Bidirectional Glenn shunt was performed with good results. A third patient had major right ventricleto-coronary artery fistulas. RVEDV, TVD, and RV-TV index before the definitive repair were $26.6 \%, 55.7 \%$, and 0.148 (Figure 4). This patient underwent reconstruction of the right ventricular outflow tract, resection of infundibular fibrous tissue, partial closure of ASD, closure of bilateral Blalock-Taussig shunts, and ligations of fistulas. Soon after coming off cardiopulmonary bypass, it became apparent that her hemodynamic values were not acceptable as she showed elevated right atrial pressure and decreased systemic blood pressure and oxygen saturation. An additional bidirectional Glenn shunt was performed. These experiences suggested that patients whose RV-TV index ranged between 0.1 and 0.2 were suitable for one and a half ventricular repair (Figure 3).

A modified Fontan operation was performed on $10 \mathrm{pa}-$ tients (Figure 2). As additional procedures, ligations of right ventricle-to-coronary artery fistulas were performed in 3 patients, repair for branch stenosis of the pulmonary artery in 3 patients, and tricuspid valvuloplasty in 1 patient. RVEDV and TVD before the Fontan-type operation ranged from $6.0 \% \mathrm{~N}$ to $25.1 \% \mathrm{~N}$ (median: $10.0 \% \mathrm{~N}$ ) and $21.4 \% \mathrm{~N}$ to 
$51.0 \% \mathrm{~N}$ (median: $40.3 \% \mathrm{~N}$ ), respectively. RV-TV index was less than 0.1 in this group of patients (Figure 3 ).

\section{Follow-up}

Among the 32 patients surviving the definitive operation, 2 patients died of congestive heart failure 2 and 9 years after the operation. Three patients had further operations: bidirectional Glenn shunt for stenosis of the right pulmonary artery 7 years after the modified Fontan operation in 1, plasty for stenosis of the left pulmonary artery 1 year after biventricular repair in 1, and release of the left pulmonary venous obstruction 10 months after biventricular repair in the other patient (Figure 2).

Actuarial survival, including noncardiac death, was $91.1 \%$ at 5 years after the initial procedure and $81.5 \%$ at 10 years.

\section{Discussion}

Surgical treatment of PA-IVS still has significant problems. Better understanding of the anatomy and hemodynamics of this lesion has resulted in improved survival after palliative and definitive operations. ${ }^{2,5,11}$ Surgical decision making is very important because the results of palliative and definitive operations are closely related to the morphology of right ventricle, tricuspid valve, and coronary arteries. ${ }^{11-}$ 13,26,33 We are developing a management protocol on the criteria for determining adequate procedures. ${ }^{16,27}$

\section{Initial Palliations}

The aims of initial palliations are to improve systemic arterial oxygenation by providing reliable pulmonary blood flow and to promote the growth of the right ventricle by establishment of transventricular blood flow. ${ }^{16,17}$

Hypoplasia of the right ventricular cavity in PA-IVS appears to be related to massive hypertrophy of the right ventricular wall in response to complete obstruction of the right ventricular outflow tract. Therefore, postnatal growth of the right ventricle depends on relief of the outflow obstruction and right ventricular hypertension. ${ }^{6,21}$ Recently, it appeared that the presence of all 3 portions of the right ventricle does not necessarily guarantee adequate right ventricular size ${ }^{15}$ and that the growth potential of the right ventricle may be lost at an early age. ${ }^{26}$ A number of authors emphasized the importance of early right ventricular decompression for patients in whom a right ventricular outflow tract could be identified. ${ }^{6,7,15,16,26}$ With the emphasis on cavity size and anatomy, the associated problems of right ventricle-to-coronary artery fistulas and coronary stenoses and/or occlusions should be considered. Right ventricular decompression may cause myocardial ischemia in patients with right ventricle-dependent coronary circulation. ${ }^{9-12}$ Gigllia and associates ${ }^{34}$ reported that right ventricular decompression was contraindicated in the presence of stenoses and/or occlusions involving both the right and left coronary systems. Precise definition of the coronary arterial anatomy is necessary for determining the indication of right ventricular decompression.

The management protocol of neonates with PA-IVS continues to be controversial. ${ }^{8,16,26}$ A variety of methods including a pulmonary valvotomy, ${ }^{1,6,7,12,15-18}$ balloon valvuloplasty, ${ }^{19,20}$ or a right ventricular outflow tract patch ${ }^{3,4,11,12}$ were used to decompress the right ventricle. We performed open transpulmonary valvotomy with the use of a balloon occlusion of the right ventricular outflow tract as a procedure of choice. ${ }^{16}$ The open transpulmonary valvotomy is preferable to the outflow tract patch or balloon valvuloplasty because it produces less ventricular damage and preserves more of the pulmonary valve with less regurgitation. $^{2,15,17}$ In addition, this procedure can be performed without cardiopulmonary bypass. ${ }^{2,12,15,17}$ We performed the open transpulmonary valvotomy as an initial palliation in 27 patients with one operative death. Eighteen of these 27 patients $(66.7 \%)$ received biventricular repair. We believe that this procedure can be performed safely and effectively. Effective transpulmonary valvotomy allows for growth of the right ventricle, annulus of the tricuspid valve, and annulus of the pulmonary valve. ${ }^{16}$ We succeeded in performing revalvotomy in 9 patients at the time of definitive repair. We tried to minimize the need for right ventricular outflow tract patch because we believe that this procedure may increase the degree of pulmonary regurgitation and, thus, potentially increase the need for further surgical intervention. ${ }^{16,27}$

In addition to right ventricular decompression, the need for a systemic-pulmonary artery shunt is an important question. ${ }^{6,16,22}$ A number of authors advocate using a systemicpulmonary artery shunt in combination with right ventricular decompression to ensure a sufficient pulmonary blood flow and still preserve a biventricular system. ${ }^{17,18}$ However, the combination of pulmonary blood flow both from the right ventricle and from a shunt could result in volume overload and left ventricular failure in some cases. ${ }^{20,22}$ Early in our series, one patient was complicated by congestive heart failure due to excessive pulmonary blood flow after the placement of a Blalock-Taussig shunt. ${ }^{16}$ Our calculated index of right ventricular development (RVDI) provided criteria for the selection of the initial palliative procedure. We reviewed the patients who underwent initial palliative operation between 1981 and $1987 .{ }^{16}$ There were 12 patients who underwent open transpulmonary valvotomy. Of these 12 patients, 4 patients required $\beta$-blocker ${ }^{31}$ and 4 required additional Blalock-Taussig shunt. The RVDI in these 4 patients who required $\beta$-blocker ranged between 0.35 and 0.7 and was lower than 0.35 in 3 of 4 patients who required additional Blalock-Taussig shunt. ${ }^{16}$ Based on the retrospective review of the patients early in this series, 9 
patients whose RVDI was lower than 0.35 underwent concomitant transpulmonary valvotomy and Blalock-Taussig shunt. Since the management protocol based on the value of RVDI had been established, none of the patients who had transpulmonary valvotomy as an initial procedure required additional Blalock-Taussig shunt.

RVDI is based on the 3 constituents including RVEDV, TVD, and RVOD. Although the pulmonary valve was incised as wide as possible at the time of transpulmonary valvotomy, there were some patients with a very narrow right ventricular outflow tract that might cause insufficient pulmonary blood flow. We tried the administration of $\beta$-blocker in such cases with good results. ${ }^{31}$ These results indicate that neither RVEDV nor TVD could be a reliable indicator in isolation for determining the initial palliative procedure. We believe that it is possible to divide clearly those patients who require transpulmonary valvotomy alone, those who require additional $\beta$-blocker, and those who require additional Blalock-Taussig shunt.

In the present study, there were 9 patients who had muscular atresia. Usually, patients with muscular atresia have hypoplastic right ventricle and frequently complicated right ventricle-dependent coronary circulation (Figure 1, $B$ ). Most of these patients become candidates for Fontantype procedure. In our series, RVEDV and RVDI in this group of patients ranged from $7.0 \% \mathrm{~N}$ to $25.1 \% \mathrm{~N}$ and 0.010 to 0.060 , respectively. We believe that a right ventricular outflow tract patch with the use of cardiopulmonary bypass for such neonates would result in poor outcomes. For patients with muscular atresia, we performed only BlalockTaussig shunt with good results.

In the present study, some of the patients who originally had only a Blalock-Taussig shunt ended up getting a biventricular repair, and 1 patient who had a valvotomy ended up getting a Fontan-type operation. These results show that RVDI is not perfect to decide the initial and final approach. However, 22 patients underwent an initial palliation with no early and no late deaths. We believe that RVDI can represent the safe and appropriate approach for the neonates with PA-IVS.

\section{Definitive Repairs}

With improved results of palliative operations, an increased number of patients were referred for a definitive operation. ${ }^{8,21}$ Definitive operations including biventricular repair, one and a half ventricular repair, or Fontan-type operation are performed to separate the pulmonary and systemic circulations to eliminate cyanosis. ${ }^{21-25}$ The most important problem in planning a strategy for the definitive repair is the fact that right ventricular growth and contribution to pulmonary flow is difficult to predict before the operation. ${ }^{11,32}$ de Leval and associates ${ }^{35}$ stated that patients with tripartite right ventricle and adequate-sized tricuspid valve (larger than the lower $99 \%$ confidence limit of the normal mean) can safely undergo a biventricular repair. On the other hand, Alboliras and associates ${ }^{21}$ stated that the presence of 3 portions did not always signify adequacy for biventricular repair and that the actual size of the tricuspid valve was an adequate index in determining the definitive procedure. They indicated that patients with a tricuspid valve circumference of greater than $70 \% \mathrm{~N}$ were good candidates for biventricular repair, and those with an annular circumference of less than $55 \% \mathrm{~N}$ should be Fontan candidates. Recently, a number of authors emphasized the importance of the Z-value of the tricuspid valve as an index of right ventricular growth. ${ }^{8,19,20}$ However, the minimal Z-value of the tricuspid valve needed to predict a biventricular repair is still controversial, and clear-cut criteria are not available for the selection of the definitive procedure. ${ }^{8,12,13,32}$ Based on a retrospective review of the first 14 patients treated before 1992, we developed a selection criteria for the definitive procedure. Since 1992, the type of definitive procedure has been decided in conformity with the value of the calculated RV-TV index. ${ }^{27,32}$ Although the size of the tricuspid valve annulus is directly proportional to the size of the right ventricular cavity in most cases, there were considerable overlaps in these values among patients who underwent the deferent types of definitive operations. ${ }^{8}$ Combining the measurement of the RVEDV and TVD created a more sensitive index, reflecting both the smaller RVEDV and smaller TVD. We divided the latest 18 patients with PAIVS into 4 groups by means of the RV-TV index, and we performed the deferent types of definitive operations with good results (Figure 3). We believe that it is possible to determine an adequate definitive procedure including biventricular repair with complete or partial closure of ASD, one and a half ventricular repair, and Fontan-type operation for patients with PA-IVS.

Although biventricular repair, when possible, is the preferred approach for patients with PA-IVS, systemic venous congestion and low cardiac output may develop in some patients with hypoplastic right ventricle after biventricular repair. The main causes of systemic venous congestion and low cardiac output include: (1) increased pulmonary vascular resistance in response to cardiopulmonary bypass, (2) sudden volume overload to the hypertrophied but smallchambered right ventricle, and (3) decreased left ventricular filling. ${ }^{24,36}$ The incorporation of maintaining ASD patency in patients undergoing biventricular repair may provide shunting blood flow from the right to the left side of the heart. This results in decreasing the volume overload on the right ventricle and improving cardiac output, while maintaining an adequate systemic oxygen saturation. After several postoperative days, the right ventricle will adapt to the new physiology, and pulmonary vascular resistance will decrease. Maintaining ASD patency in the acute phase of 
the postoperative period may improve the early outcome in these patients. ${ }^{4,36}$ Laks and associates ${ }^{36}$ performed an adjustable ASD technique in 5 patients with right ventricular size between one third and two thirds of the size of left ventricle. They adjusted the ASD size until an acceptable right atrial pressure $(<15 \mathrm{~mm} \mathrm{Hg})$ was obtained, while maintaining a systemic oxygen saturation of $>85 \%$. We performed biventricular repair with partial closure of ASD in 8 patients with moderately hypoplastic right ventricle (RVEDV: $35.0 \% \mathrm{~N}-69.0 \% \mathrm{~N}$, TVD: $47.0 \% \mathrm{~N}-67.0 \% \mathrm{~N}$ ). We closed the ASD using a Dacron patch with a 4- to 7-mm hole. Spontaneous closure of the fenestration was confirmed by follow-up echocardiography. There were no clinical or echocardiographic findings suggesting thrombus formation at the site of the fenestrated patch. We believe that partial closure of ASD using a fenestrated patch is a useful adjunct to allow for a smooth transition to biventricular repair in patients with moderately hypoplastic right ventricle.

For patients with a right ventricle that is functional but unable to support the entire pulmonary blood flow, one and a half ventricular repair may be preferable for definitive palliation. ${ }^{12}$ This approach allows the maintenance of equal pulmonary and systemic flows, and the bidirectional Glenn anastomosis simultaneously reduces the volume load on the right ventricle. ${ }^{24,25}$ The indications for this approach in patients with PA-IVS are not yet completely clear. We performed one and a half ventricular repair on 3 patients. RVEDV and TVD ranged from $26.6 \% \mathrm{~N}$ to $35.0 \% \mathrm{~N}$ and $55.0 \% \mathrm{~N}$ to $64.0 \% \mathrm{~N}$, respectively, in these 3 patients. There was no improvement in cyanosis after biventricular repair with partial closure of ASD in 2 patients whose RV-TV indexes were 0.148 and 0.165 . In another patient in whom initial valvotomy had been performed at 4 months of age, right heart failure developed 6 years after the biventricular repair with partial closure of ASD. RV-TV index decreased to 0.175 when she showed signs of right heart failure. These 3 patients showed a marked improvement after the addition of a bidirectional Glenn shunt. These results suggest that one and a half ventricular repair seems to be a procedure of choice for patients whose RV-TV index ranges between 0.1 and 0.2 .

\section{Study Limitations}

Simpson's rule method has been used with accuracy to calculate right ventricular volume in patients with normal right heart or in patients with pulmonary stenosis. Further validation of the accuracy and applicability of this method is needed in patients with PA-IVS. Nakazawa and associates ${ }^{29}$ stated that Simpson's rule method can be applied to pulmonary stenosis with small right ventricle and that it is helpful in patient management. We believe that results of our experiences demonstrate that this method is helpful in management of patients with PA-IVS.

\section{Conclusions}

We treated patients with PA-IVS according to a management protocol based on our quantitative assessment of right ventricular morphology with good results. Therefore, we believe that our calculated RVDI for initial palliation and RV-TV index for later definitive operation are useful indicators for the selection of adequate procedures in patients with PA-IVS.

For patients with RVDI $>0.7$, open transpulmonary valvotomy is recommended as an initial palliation. When RVDI is between 0.35 and $0.7, \beta$-blocker will be needed in addition to valvotomy. When RVDI is lower than 0.35, concomitant valvotomy and Blalock-Taussig shunt is recommended. For patients with muscular atresia of the right ventricular outflow tract or right ventricle-dependent coronary circulation, we perform only a Blalock-Taussig shunt as a procedure of choice.

In terms of staged definitive repair, complete biventricular repair will be accomplished in patients with the RV-TV index $>0.4$. For patients with the RV-TV index ranging between 0.2 and 0.4 , we advocate the biventricular repair with partial closure of ASD. When the RV-TV index is between 0.1 and 0.2 , one and a half ventricular repair seems to be a procedure of choice. For patients with the RV-TV index of lower than 0.1, Fontan-type procedure should be performed.

\section{References}

1. de Leval M, Bull C, Stark J, Anderson RH, Taylor JFN, Macartney FJ. Pulmonary atresia and intact ventricular septum: surgical management based on a revised classification. Circulation. 1982;66:272-80.

2. Leung MP, Mok C, Lee J, Lo RNS, Cheung H, Chiu C. Management evolution of pulmonary atresia and intact ventricular septum. Am J Cardiol. 1993;71:1331-6.

3. Coles JG, Freedom RM, Lightfoot NE, et al. Long-term results in neonates with pulmonary atresia and intact ventricular septum. Ann Thorac Surg. 1989;47:213-7.

4. Foker JE, Braunlin EA, St. Cry JA, et al. Management of pulmonary atresia with intact ventricular septum. J Thorac Cardiovasc Surg. 1986;92:706-15.

5. Giglia TM, Jenkins KJ, Matitiau A, et al. Influence of right heart size on outcome in pulmonary atresia with intact ventricular septum. Circulation. 1993;88:2248-56.

6. Lewis AB, Wells W, Lindesmith GG. Right ventricular growth potential in neonates with pulmonary atresia and intact ventricular septum. J Thorac Cardiovasc Surg. 1986;91:835-40.

7. Bull C, Kostelka M, Sorensen K, de Leval M. Outcome measures for the neonatal management of pulmonary atresia with intact ventricular septum. J Thorac Cardiovasc Surg. 1994;107:359-66.

8. Hanley FL, Sade RM, Blackstone EH, Kirklin JW, Freedom RM, Nanda NC. Outcomes in neonatal pulmonary atresia with intact ventricular septum. A multiinstitutional study. J Thorac Cardiovasc Surg. 1993;105:406-27.

9. Gentles TL, Colan SD, Giglia TM, Mandell VS, Mayer JE Jr, Sanders SP. Right ventricular decompression and left ventricular function in pulmonary atresia with intact ventricular septum: the influence of less extensive coronary anomalies. Circulation. 1993;88:183-8.

10. Akagi T, Benson LN, Williams WG, Trusler GA, Freedom RM. Ventriculocoronary arterial connections in pulmonary atresia with intact ventricular septum, and their influences on ventricular performance and clinical course. Am J Cardiol. 1993;72:586-90. 
11. Jahangiri M, Zurakowski D, Bichell D, Mayer JE, del Nido PJ, Jonas RA. Improved results with selective management in pulmonary atresia with intact ventricular septum. J Thorac Cardiovasc Surg. 1999;118: 1046-55.

12. Henaine R. Pulmonary atresia and intact ventricular septum: early, mid and long term outcomes. A thirtieth bi-institutional study. Université de Bordeaux. Thése n 3056. 2001. p. 1-133.

13. Rychik J, Levy H, Gaynor JW, DeCampli WM, Spray TL. Outcome after operations for pulmonary atresia with intact ventricular septum. J Thorac Cardiovasc Surg. 1998;116:924-31.

14. Sano S, Ishino K, Kawada M, Fujisawa E, Kamada M, Ohtsuki S. Staged biventricular repair of pulmonary atresia or stenosis with intact ventricular septum. Ann Thorac Surg. 2000;70:1501-6.

15. Hawkins JA, Thorne JK, Boucek MM, et al. Early and late results in pulmonary atresia and intact ventricular septum. $J$ Thorac Cardiovasc Surg. 1990;100:492-7.

16. Yamaguchi M, Hosokawa Y, Ohashi H, Oshima Y, Tsukube T. Assessment of right ventricular growth in infants with pulmonary atresia and intact ventricular septum. In: Crupi G, Parenzan L, Anderson RH, editors. Perspectives in pediatric cardiology. Vol 2. New York: Futura Publishing Co Inc; 1989. p. 116-21.

17. Shaddy RE, Sturtevant JE, Judd VE, McGough EC. Right ventricular growth after transventricular pulmonary valvotomy and central aortopulmonary shunt for pulmonary atresia and intact ventricular septum. Circulation. 1990;82(IV):157-63.

18. Joshi SV, Brawn WJ, Mee RBB. Pulmonary atresia with intact ventricular septum. J Thorac Cardiovasc Surg. 1986;91:192-9.

19. Wang JK, Wu MH, Chang CI, Chen YS, Lue HC. Outcomes of transcatheter valvotomy in patients with pulmonary atresia and intact ventricular septum. Am J Cardiol. 1999;84:1055-60.

20. Ovaert C, Qureshi SA, Rosenthal E, Baker EJ, Tynan M. Growth of the right ventricle after transcatheter pulmonary valvotomy in neonates and infants with pulmonary atresia and intact ventricular septum. J Thorac Cardiovasc Surg. 1998;115:1055-62.

21. Alboliras ET, Julsrud PR, Danielson GK, et al. Definitive operation for pulmonary atresia with intact ventricular septum: results in twenty patients. J Thorac Cardiovasc Surg. 1987;93:454-64.

22. McCaffrey FM, Leatherbury L, Moore HV. Pulmonary atresia and intact ventricular septum: definitive repair in the neonatal period. J Thorac Cardiovasc Surg. 1991;102:617-23.

23. Najm HK, Williams WG, Coles JG, Rebeyka IM, Freedom RM. Pulmonary atresia with intact ventricular septum: results of the Fontan procedure. Ann Thorac Surg. 1997;63:669-75.

24. Kreutzer C, Mayorquim RC, Kreutzer GOA, et al. Experience with one and a half ventricle repair. J Thorac Cardiovasc Surg. 1999;117:662-8.
25. Reddy VM, McElhinney DB, Silverman NH, Marianeschi SM, Hanley FL. Partial biventricular repair for complex congenital heart defects: an intermediate option for complicated anatomy or functionally borderline right complex heart. J Thorac Cardiovasc Surg. 1998;116:21-7.

26. Mainwaring RD, Lamberti JJ. Pulmonary atresia with intact ventricular septum: surgical approach based on ventricular size and coronary anatomy. J Thorac Cardiovasc Surg. 1993;106:733-8.

27. Yamaguchi M, Ohashi H, Oshima Y, Yoshimura N. Transpulmonary open-valvotomy and later definitive repair for pulmonary atresia with intact ventricular septum. Proceedings of 2 nd World Congress of Pediatric Cardiology and Cardiac Surgery. Kobe, Japan. 1998. p. 798-800.

28. Graham TP Jr, Jarmakani JM, Atwood GF, Canent RV Jr. Right ventricular volume determinations in children: normal values and observations with volume or pressure overload. Circulation. 1973;47: 144-53.

29. Nakazawa M, Marks RA, Isabel-Jones J, Jarmakani JM. Right and left ventricular volume characteristics in children with pulmonary stenosis and intact ventricular septum. Circulation. 1976;53:884-90.

30. Bull C, de Leval M, Mercanti C, Macartney FJ, Anderson RH. Pulmonary atresia and intact ventricular septum: a revised classification. Circulation. 1982;66:266-72.

31. Yamaguchi M, Ohashi H, Tachibana H, Hosokawa Y, Tei T, Mito H. Effect of $\beta$-blocker administration in the post-valvotomy management of infants with pulmonary atresia and intact ventricular septum. Kobe J Med Sci. 1987;33:235-9.

32. Ohashi H, Yamaguchi M, Imai M, Oshima Y, Kumamoto T, Sugimoto I. Additional palliative operation and staged definitive operation for pulmonary atresia with intact ventricular septum. Rinsyo Kyobu Geka. 1994;14:202-6.

33. Minich LL, Tani LY, Ritter S, Williams RV, Shaddy RE, Hawkins JA. Usefulness of the preoperative tricuspid/mitral valve ratio for predicting outcome in pulmonary atresia with intact ventricular septum. Am J Cardiol. 2000;85:1325-8.

34. Giglia TM, Mandell VS, Connor AR, Mayer JE Jr, Lock JE. Diagnosis and management of right ventricle-dependent coronary circulation in pulmonary atresia with intact ventricular septum. Circulation. 1992; 86:1516-28.

35. de Leval M, Bull C, Hopkins R, et al. Decision making in the definitive repair of the heart with a small right ventricle. Circulation. 1985; 72(Suppl II):II52-9

36. Laks H, Pearl JM, Drinkwater DC, et al. Partial biventricular repair of pulmonary atresia with intact ventricular septum. Circulation. 1992; 86(Suppl II):II159-66. 